\title{
Mild cognitive impairment and quality of life in the oldest old: a closer look
}

\author{
Felix S. Hussenoeder ${ }^{1}$ (D) Ines Conrad ${ }^{1}$ - Susanne Roehr ${ }^{1} \cdot$ Angela Fuchs $^{2} \cdot$ Michael Pentzek $^{2} \cdot$ Horst Bickel $^{3}$. \\ Edelgard Moesch $^{3}$. Siegfried Weyerer ${ }^{4} \cdot$ Jochen Werle $^{4} \cdot$ Birgitt Wiese $^{5} \cdot$ Silke Mamone $^{5}$. Christian Brettschneider ${ }^{6}$. \\ Kathrin Heser ${ }^{7} \cdot$ Luca Kleineidam $^{7} \cdot$ Hanna Kaduszkiewicz $^{8} \cdot$ Marion Eisele $^{9} \cdot$ Wolfgang Maier $^{10} \cdot$ Michael Wagner $^{7,11}$. \\ Martin Scherer $^{9} \cdot$ Hans-Helmut König $^{6} \cdot$ Steffi G. Riedel-Heller ${ }^{1}$
}

Accepted: 9 January 2020 / Published online: 28 January 2020

(c) The Author(s) 2020

\begin{abstract}
Purpose Mild cognitive impairment (MCI) is a widespread phenomenon, especially affecting older individuals. We will analyze in how far MCI affects different facets of quality of life (QOL).

Methods We used a sample of 903 participants (110 with MCI) from the fifth follow-up of the German Study on Ageing, Cognition, and Dementia in Primary Care Patients (AgeCoDe), a prospective longitudinal study, to analyze the effects of MCI on different facets of the WHOQOL-OLD. We controlled for age, gender, marital status, education, living situation, daily living skills, and the ability to walk, see, and hear.

Results Univariate analyses showed that individuals with MCI exhibited lower QOL with regard to the facets autonomy; past, present, and future activities; social participation; and intimacy, but less fears related to death and dying. No significant difference was shown with regard to the facet sensory abilities. In multivariate analyses controlling for age, gender, marital status, education, living situation, daily living skills, and the ability to walk, see and hear, MCI-status was significantly associated with QOL in the facet autonomy.

Conclusion Effects of MCI go beyond cognition and significantly impact the lives of those affected. Further research and practice will benefit from utilizing specific facets of QOL rather than a total score.
\end{abstract}

Keywords MCI $\cdot$ Quality of life $\cdot$ Older people $\cdot$ WHOQOL-OLD

Felix S. Hussenoeder and Ines Conrad shared first authorship. Hans-Helmut König and Steffi G. Riedel-Heller shared last authorship.

Felix S. Hussenoeder

Felix.Hussenoeder@medizin.uni-leipzig.de

1 Institute of Social Medicine, Occupational Health and Public Health, University of Leipzig, Ph.-Rosenthal-Str. 55, 04103 Leipzig, Germany

2 Institute of General Practice, Medical Faculty, Heinrich-Heine-University Düsseldorf, Düsseldorf, Germany

3 Department of Psychiatry, Technical University of Munich, Munich, Germany

4 Central Institute of Mental Health, Medical Faculty Mannheim/Heidelberg University, Mannheim, Germany

5 Institute for General Practice, Hanover Medical School, Hanover, Germany

6 Department of Health Economics and Health Services Research, University Medical Centre Hamburg-Eppendorf, Hamburg, Germany
7 Clinic for Neurodegenerative Diseases and Geriatric Psychiatry, University Hospital of Bonn, Bonn, Germany

8 Institute of General Practice, Medical Faculty, Kiel University, Kiel, Germany

9 Department of Primary Medical Care, Center for Psychosocial Medicine, University Medical Center Hamburg-Eppendorf, Hamburg, Germany

10 Clinic for Psychiatry and Psychotherapy, University Hospital of Bonn, Bonn, Germany

11 German Center for Neurodegenerative Diseases (DZNE), Bonn, Germany 


\section{Introduction}

Age-related cognitive decline is a widespread phenomenon, and there is an adjusted overall prevalence of $16 \%$ (effect size, $95 \%$ CI 12-20\%), increasing with age, for mild cognitive impairment (MCI) [10]. In the light of demographic change and an aging society, cases of MCI are likely to rise. It is therefore crucial to understand the subjective implications of MCI for those affected. In the long run, this will help to develop suitable interventions and support.

Quality of life (QOL) is a key concept for understanding the subjective dimension of $\mathrm{MCI}$ and the impact it has on those affected. Most researchers agree on a multidimensional concept including physical, psychological, and social aspects as well as those related to daily life activities [6, 25]. In addition, over the lifespan, different aspects become relevant for QOL. Since our interest is in the oldest old, we assessed QOL with the WHOQOL-OLD, an instrument that specifically addresses domains that are relevant for individuals older than 60 years [4]: (1) sensory impairments and in how far they affect daily life as well as the ability to communicate with others (sensory abilities); (2) the amount of autonomy, independent decision taking, and ability to influence one's future (autonomy); (3) received appreciation and felt satisfaction for accomplishments in life as well as a general future outlook (past, present, and future activities); (4) level of activity and possibilities to participate (social participation); (5) fears and attitudes related to death and dying (death and dying); and (6) possibilities to experience love and affection (intimacy).

Research comparing quality of life (QOL) of individuals with and without MCI is rare and inconsistent. While some studies report no difference between the two groups [19, 23], others report lower QOL for people diagnosed with MCI in almost all areas [28, 31]. Especially individuals who are aware of their MCI diagnosis seem to have reduced QOL independent of impairment severity [27]. Unfortunately, most studies refer to highly selective samples from memory clinics or nursing homes [19] or are focused on healthrelated QOL $[14,17,22]$. Only few studies are representative for the general population [15]. In addition, research on $\mathrm{MCI}$ is often centered around the idea of MCI as a risk factor for subsequent dementia, rather than on the direct effects of MCI on the individuals [2, 24, 34].

\section{Aims of the study}

In this study, we want to investigate how MCI is associated with QOL. We will therefore (1) analyze the differences between individuals with and without MCI diagnosis in
QOL in general and with regard to all six facets of QOL, i.e., sensory abilities; autonomy; past, present, and future activities; social participation; fears related to death and dying; and intimacy, and (2) analyze the predictive effect of MCI on the scores of QOL facets controlling for wellestablished variables like age and marital status.

\section{Methods}

\section{Study design and sample}

We used data derived from the German Study on Ageing, Cognition, and Dementia in Primary Care Patients (AgeCoDe), a prospective longitudinal study on the early detection of MCI and dementia in general practices that was conducted as a collaboration of six study centers-Hamburg, Bonn, Duesseldorf, Leipzig, Mannheim, Munich. Baseline assessment took place in 2003-2004, and participants were reassessed in follow-ups every 18 months until 2013. Participants were recruited based on the following inclusion criteria: (1) aged 75 and over, (2) absence of dementia, (3) at least one GP contact within the last year. Patients were excluded, if (4) GP consultations were home visits only, (5) patients lived in a nursing home, (6) GPs diagnosed a severe illness which they would deem fatal within 3 months, (7) patients were deaf, blind, lacked sufficient proficiency in the German language, or lacked the ability to provide informed consent.

Out of a randomly selected, cross-sectional sample of $N=6619$ GP patients, a total of $N=3327$ eligible persons consented to participate and were assessed at baseline through structured clinical interviews. The design of the study has been described in detail elsewhere [18].

For the present study, we utilized data from Follow-up 5, collected between 10/2010 and 11/2012, as here QOL had been assessed. 2424 out of 3327 participants from baseline assessment were not part of Follow-up 5: 1985 related to study attrition mainly due to death, 182 related to unclear MCI-status, 254 related to incomplete WHOQOL measurement, and three related to missing control variables. The final sample comprised a total of 903 participants. A detailed depiction of the sample selection process is found in Fig. 1.

\section{Assessment}

Structured clinical interviews were conducted by trained psychologists and physicians at participants' homes. The interviewers assessed control variables age, gender, marital status, education, and current living situation. Research shows that higher age, better education, being married, being male, and living with a partner can be associated with better quality of life $[13,21,30]$. In addition, the ability to hear, see 
Fig. 1 Process of sample selection

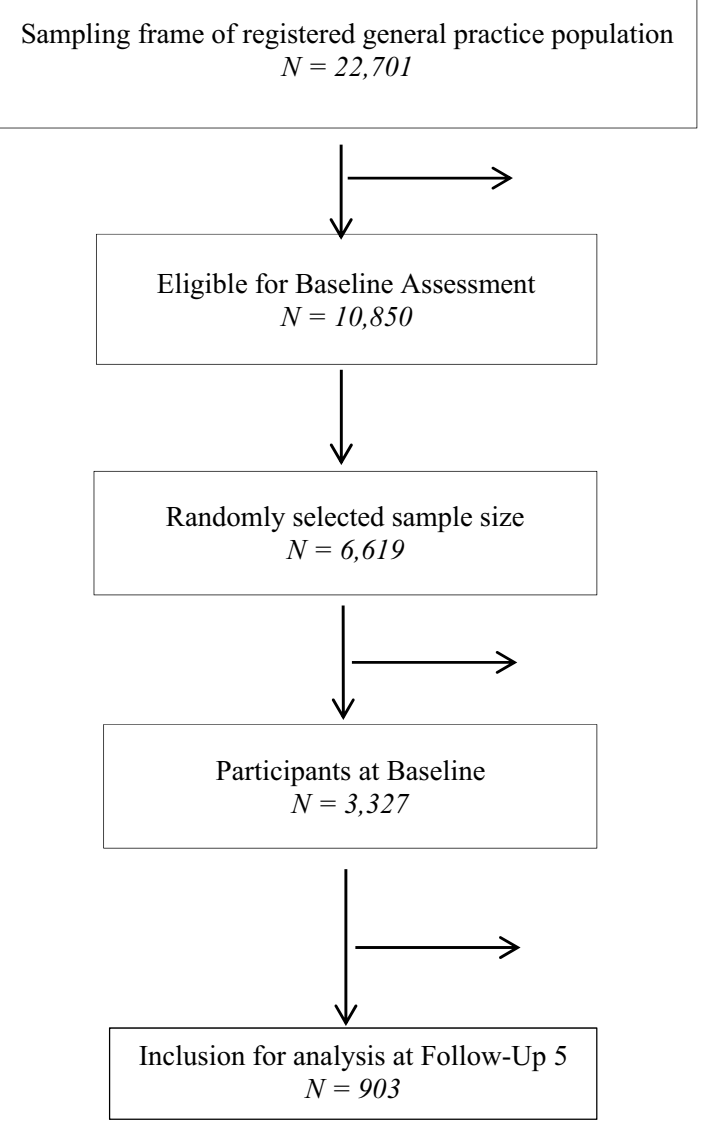

$$
\begin{gathered}
\text { Non-eligible } \\
N=11,851
\end{gathered}
$$

Irregular patients

Only home visits

Deceased

No ability to consent

Severely ill

Deaf or blind

Language

Other reasons

Not documented

\begin{tabular}{|lc|}
\hline \multicolumn{2}{|c|}{$\begin{array}{c}\text { Nonparticipants } \\
N=3,292\end{array}$} \\
\multicolumn{1}{|c|}{$\begin{array}{l}\text { No response } \\
\text { Refused }\end{array}$} & 1,517 \\
& 1,775 \\
\hline
\end{tabular}

\section{Exclusion}

$N=2,424$

Attrition from Baseline No MCI assessment and walk, and the ability to function in daily life-which are all positively associated with quality of life $[7,9,16,26]-$ were assessed, and cognitive tests were conducted.

\section{Cognitive assessment and $\mathrm{MCl}$-status}

MCI was diagnosed according to consensus criteria proposed by the International Working Group on Mild Cognitive Impairment [32]. They include the following: (1) absence of dementia according to DSM-IV or ICD-10, (2) evidence of cognitive decline: self-rating or informant report and impairment on objective cognitive tasks and/or evidence of decline over time on objective cognitive tasks, and (3) preserved baseline activities of daily living or only minimal impairment in complex instrumental functions. Dementia according to DSM-IV was excluded with structured interviews (SIDAM) [35]. The criterion of subjective cognitive complaints was fulfilled when the question on subjective memory impairment was positively answered. The SIDAM neuropsychological test battery was used to assess objective cognitive decline. Impairment in all four cognitive domains was defined as test performance of more than 1 SD below the main value for age- and education-specific norms. The functional activities were assessed with the SIDAM-ADL Scale. Participants with only one or no impairments in the 14 items of the SIDAMADL Scale were regarded as functionally unimpaired.

\section{Quality of life}

Quality of life was assessed using the WHOQOL-OLD, a test that had been specifically designed to assess the subjective QOL of adults over the age of 60. It includes six facets, with four items each: sensory abilities; autonomy; past, present, and future activities (assesses received appreciation and felt satisfaction for accomplishments in life as well as a general future outlook); social participation; fears related to death and dying; and intimacy [4, 5]. Items can be answered from 1, representing absolute disagreement, to 5 , i.e., absolute agreement. During analysis inverse items were recorded before an average was calculated for every facet. This facet average was then multiplied by four, resulting in a score between four and 20 which was then transformed into a score between 0 and 100. Higher scores represent better QOL. 


\section{Instrumental abilities}

The ability to carry out instrumental activities of daily living (IADL) with the Lawton-and-Brody IADL scale [1]. The scale includes abilities related to using the telephone, shopping, food preparation, housekeeping, laundry, mode of transportation, and responsibility for own medications and finances.

\section{Statistical analyses}

Independent $t$ tests and the Mann-Whitney test (death and dying) were used to analyze QOL differences between participants with and without MCI diagnosis.

We used Stata 16 and multiple linear regressions to analyze the effect of MCI on QOL facets sensory abilities; autonomy; past, present, and future activities; social participation; and intimacy controlling for age, gender, marital status, living situation, ability to carry out instrumental activities of daily living (IADL), and the ability to walk, see and hear. Since there was right-censoring in the observed range of death and dying, we used Tobit regression for that specific facet. The Huber-White sandwich estimator [8] was applied in all regressions to obtain a robust variance estimate that adjusts for within-cluster correlation with regard to study centers.

\section{Results}

\section{Descriptive characteristics}

After excluding participants without scores on the main variables, our dataset contained 903 individuals with 603 females (66.8\%) and $110(12.2 \%)$ with MCI. Table 1 shows the general characteristics of the study population. The MCI group was slightly older, less likely to be married, slightly better educated, exhibited lower IADL scores and was more likely to have hearing problems and considerable or severe walking impairments.

\section{Group comparisons: quality of life in non-MCI vs. MCI}

Table 2 shows comparisons between the MCI and the non-MCI groups for all six facets of QOL, indicating significant differences for all facets besides sensory abilities. While participants with MCI in general exhibited reduced QOL, they experienced less fears related to death and dying.

\section{$\mathrm{MCl}$ as a predictor of $\mathrm{QOL}$}

Table 3 shows the regression analysis with MCI as a predictor of QOL facets and control variables. Results show that age, gender, marital status, and seeing and hearing abilities showed only little relevance for the prediction of QOL facets (besides the expectable prediction of sensory abilities). Education significantly predicted two facets (autonomy, past, present, and future activities), IADL three (autonomy, past, present, and future activities, social participation), and walking ability predicted three facets (sensory abilities, past, present, and future activities, social participation). MCI-status exhibited a significant, negative impact on autonomy. Since our predictors explain almost no variance in the outcome of death and dying, the effects of specific predictors will not be interpreted.

\section{Discussion}

In our sample, $12.2 \%$ of participants were diagnosed with MCI. This relatively low percentage, compared to other current studies [10], is a consequence of the application of strict criteria for MCI diagnosis [32]. Our univariate comparison of participants with and without MCI showed significant differences for QOL for the facets autonomy; past, present, and future activities; social participation; death and dying; and intimacy. With the exception of death and dying, the non-MCI group constantly showed higher levels of QOL. This could point to the fact that in case of MCI, existential fears are to some extent replaced by more proximate fears and worries related to daily living. The regression analysis, including multiple control variables, confirmed MCI diagnosis as a significant predictor of impaired QOL in the facet autonomy.

Our results from the univariate analysis show that $\mathrm{MCI}$ has a tendency to affect QOL in a negative way. This matches with other studies where MCI had a negative association with psychological QOL [20] and with QOL measured via subject and informant ratings [29]. The fact that there was no difference between $\mathrm{MCI}$ and non-MCI groups in terms of QOL with regard to sensory abilities is most likely a consequence of the strong impact of seeing and hearing abilities on this specific facet. In the multivariate analysis, we can find an impact of MCI-status on the facet autonomy. This makes sense, since the decline of cognitive abilities, and the fear of further deterioration, directly affects individuals' ability to live independently and take own decisions. In addition, some researchers emphasize the importance of promoting autonomy in order to increase health-related QOL of people with MCI [3]. Since $\mathrm{MCI}$ is far less severe than dementia and more heterogenic in outcome [32], impairments are smaller and less visible to others. Therefore, MCI may not so much affect social interactions 
Table 1 General characteristics of the study population

\begin{tabular}{|c|c|c|c|}
\hline & Total group $(\mathrm{N}=903)$ & No MCI $(\mathrm{N}=793)$ & $\operatorname{MCI}(\mathrm{N}=110)$ \\
\hline Age & $86.5(3.1)$ & $86.3(2.9)$ & $87.9(3.8)^{* * *}$ \\
\hline Female & $603(66.8 \%)$ & $530(66.8 \%)$ & $73(66.4 \%)$ n.s \\
\hline Marital status & & & n.s \\
\hline Single & $59(6.5 \%)$ & $51(6.4 \%)$ & $8(7.3 \%)$ \\
\hline Married & $279(30.9 \%)$ & $250(31.5 \%)$ & $29(26.4 \%)$ \\
\hline Divorced & $49(5.4 \%)$ & $38(4.8 \%)$ & $11(10.0 \%)$ \\
\hline Widowed & $516(57.1 \%)$ & $454(57.3 \%)$ & $62(56.4 \%)$ \\
\hline Education $^{\mathrm{a}}$ & & & $* * *$ \\
\hline Low & $489(54.2 \%)$ & $460(58.8 \%)$ & $29(26.4 \%)$ \\
\hline Medium & $292(32.3 \%)$ & $228(28.8 \%)$ & $64(58.2 \%)$ \\
\hline High & $122(13.5 \%)$ & $105(13.2 \%)$ & $17(15.5 \%)$ \\
\hline Living situation & & & n.s \\
\hline Alone & $475(52.6 \%)$ & $417(52.6 \%)$ & $58(52.7 \%)$ \\
\hline With partner & $283(31.3 \%)$ & $252(31.8 \%)$ & $31(28.2 \%)$ \\
\hline With relatives or others & $55(6.1 \%)$ & $46(5.8 \%)$ & $9(8.2 \%)$ \\
\hline Assisted, retirement/nursing home & $95(10.5 \%)$ & $83(10.0 \%)$ & $12(10.8 \%)$ \\
\hline MCI & $110(12.2 \%)$ & $0(0 \%)$ & $110(100 \%)$ \\
\hline Instrumental Activities (IADL) ${ }^{\mathrm{b}}$ & $6.6(1.7)$ & $6.7(1.6)$ & $5.7(2.2)^{* * *}$ \\
\hline Problems walking & & & $* *$ \\
\hline No impairment & $370(41.0 \%)$ & $336(42.4 \%)$ & $34(30.9 \%)$ \\
\hline Mild impairment & $437(48.4 \%)$ & $382(48.2 \%)$ & $55(50.0 \%)$ \\
\hline Considerable/severe impairment & $96(10.7 \%)$ & $75(9.5 \%)$ & $21(19.1 \%)$ \\
\hline Problems seeing & & & n.s \\
\hline No impairment & $699(77.4 \%)$ & $608(76.7 \%)$ & $91(82.7 \%)$ \\
\hline Mild impairment & $151(16.7 \%)$ & $135(17.0 \%)$ & $16(14.5 \%)$ \\
\hline Considerable/severe impairment & $53(5.9 \%)$ & $50(6.3 \%)$ & $3(2.7 \%)$ \\
\hline Problems hearing & & & $*$ \\
\hline No impairment & $464(51.4 \%)$ & $418(52.7 \%)$ & $46(41.8 \%)$ \\
\hline Mild impairment & $417(46.2 \%)$ & $358(45.1 \%)$ & $59(53.6 \%)$ \\
\hline Considerable/severe impairment & $22(2.4 \%)$ & $17(2.2 \%)$ & $5(4.5 \%)$ \\
\hline
\end{tabular}

Continuous variables are given as mean (standard deviation), and $p$ values refer to independent $t$ tests; categorical variables are displayed as numbers (percentages), and $p$ values refer to Chi-square tests

$M C I$ mild cognitive impairment

${ }^{*} p \leq 0.05 ; * * p \leq 0.01 ; * * * p \leq 0.001$

${ }^{a}$ Education classification according to the Comparative Analysis of Social Mobility in Industrial Nations (CASMIN)

${ }^{\mathrm{b}}$ Representative score of the German population $=6.7$ (SD: 1.7) $($ Conrad et al. 2016)

\begin{tabular}{llll}
\hline Dimension & No MCI $(N=793)$ & MCI $(N=110)$ & Test-statistic \\
\hline Total & $68.81(.43)$ & $66.23(1.17)$ & $\boldsymbol{t}(\mathbf{9 0 1})=\mathbf{2 . 1 0}, \boldsymbol{p}=\mathbf{. 0 3 8}$ \\
Sensory abilities & $68.09(.75)$ & $65.18(2.05)$ & $t(897)=1.36, p=.175$ \\
Autonomy & $68.89(.60)$ & $63.21(1.73)$ & $\boldsymbol{t}(\mathbf{8 9 9})=\mathbf{3 . 2 5}, \boldsymbol{p}=\mathbf{. 0 0 1}$ \\
Past, present, and future & $69.04(.53)$ & $65.39(1.51)$ & $\boldsymbol{t}(\mathbf{8 9 3})=\mathbf{2 . 4 1}, \boldsymbol{p}=\mathbf{. 0 1 6}$ \\
$\quad$ & & \\
activities & $68.34(.61)$ & $64.03(1.60)$ & $\boldsymbol{t}(\mathbf{8 9 5})=\mathbf{2 . 5 0 ,} \boldsymbol{p}=\mathbf{. 0 1 3}$ \\
Social participation & $68.10(.86)$ & $73.36(2.16)$ & $\mathbf{U}=\mathbf{3 7 , 5 6 2 ,} z=\mathbf{2 . 1 7}, \boldsymbol{p}=\mathbf{. 0 3 0} *$ \\
Death and dying & $70.58(.74)$ & $66.28(1.85)$ & $\boldsymbol{t}(\mathbf{8 8 6})=\mathbf{2 . 0 3}, \boldsymbol{p}=\mathbf{. 0 4 3}$ \\
\hline
\end{tabular}

MCI mild cognitive impairment

*Since criteria for the independent $t$ test were not fulfilled, the Mann-Whitney test was used 
Table 3 Impact of MCI, sociodemographic and health variables on facets of QOL (unstandardized regression coefficients)

\begin{tabular}{|c|c|c|c|c|c|c|c|}
\hline Dimension & Total $(N=903)$ & $\begin{array}{l}\text { Sensory } \\
\text { abilities } \\
(N=899)\end{array}$ & $\begin{array}{l}\text { Autonomy } \\
(N=901)\end{array}$ & $\begin{array}{l}\text { Past, present, future } \\
\text { activities }(N=895)\end{array}$ & $\begin{array}{l}\text { Social } \\
\text { participation } \\
(N=897)\end{array}$ & $\begin{array}{l}\text { Death and } \\
\text { dying }^{\text {a }} \\
(N=899)\end{array}$ & Intimacy $(N=888)$ \\
\hline Constant & 22.51 & 55.74 & 29.45 & 24.86 & 17.00 & 4.72 & 0.36 \\
\hline MCI & -1.50 & -1.84 & $-4.23^{*}$ & -2.10 & -0.95 & $5.25 *$ & -4.32 \\
\hline Age & $0.43^{*}$ & 0.20 & 0.33 & 0.40 & 0.44 & 0.64 & $0.61 *$ \\
\hline Gender & 1.00 & -0.19 & -1.38 & 0.94 & $2.39 *$ & $7.98 * *$ & -3.13 \\
\hline \multicolumn{8}{|l|}{ Marital status (vs. single) } \\
\hline Married & $8.25 *$ & 3.60 & 2.20 & 8.95 & 8.19 & $10.71 *$ & $17.10 *$ \\
\hline Divorced & 2.02 & -0.34 & 4.20 & 0.98 & 3.10 & -0.08 & 4.01 \\
\hline Widowed & $5.73 *$ & 1.42 & 2.61 & 6.29 & 4.98 & $10.43 * *$ & $9.43 *$ \\
\hline \multicolumn{8}{|l|}{ Education (vs. low) } \\
\hline Medium & 0.97 & 2.13 & 1.42 & -0.14 & -0.11 & 0.19 & 1.91 \\
\hline High & 1.44 & 2.04 & $5.31 *$ & $1.79 *$ & 0.97 & $-3.61 * * *$ & 1.35 \\
\hline \multicolumn{8}{|c|}{ Living situation (vs. alone) } \\
\hline With partner & -0.06 & -0.90 & -2.07 & -0.69 & -2.34 & -1.08 & 6.33 \\
\hline With relatives or others & $3.68 *$ & 2.60 & 1.70 & 3.98 & 2.24 & $8.61^{*}$ & 6.39 \\
\hline $\begin{array}{l}\text { Assisted, retirement/ } \\
\text { nursing home }\end{array}$ & 0.72 & 3.95 & -0.67 & 1.14 & -0.014 & -1.33 & 1.31 \\
\hline $\begin{array}{l}\text { Daily living skills } \\
\text { (IADL) }\end{array}$ & $1.10^{*}$ & 0.68 & $1.87 *$ & $0.98 *$ & $2.34 * *$ & 0.09 & 0.74 \\
\hline \multicolumn{8}{|c|}{ Walking (vs. no impairment) } \\
\hline Mild impairment & $-4.07 * *$ & $-4.03 *$ & -4.63 & $-3.88 * * *$ & $-9.17 * * *$ & -3.24 & -0.79 \\
\hline Considerable/severe & $-4.92 *$ & -2.87 & -7.29 & $-6.88 * *$ & $-16.45^{* *}$ & 2.51 & 1.90 \\
\hline \multicolumn{8}{|l|}{ Seeing (vs. no impairment) } \\
\hline Mild impairment & $-2.93 *$ & $-8.06 * *$ & -0.88 & -2.47 & -2.22 & -3.16 & -1.41 \\
\hline Considerable/severe & $-4.48^{*}$ & $-22.66 * * *$ & -3.01 & 0.71 & $-6.67 *$ & 2.71 & 3.18 \\
\hline \multicolumn{8}{|c|}{ Hearing (vs. no impairment) } \\
\hline Mild impairment & $-3.66 * *$ & $-14.64 * * *$ & -1.99 & -1.88 & $-2.56^{*}$ & -0.29 & -0.54 \\
\hline Considerable/severe & $-5.06^{*}$ & $-25.96 * * *$ & -0.35 & 0.62 & 2.64 & -6.01 & -1.45 \\
\hline$R^{2}$ & 0.15 & 0.26 & 0.13 & 0.10 & 0.27 & 0.01 & 0.10 \\
\hline
\end{tabular}

The Huber-White sandwich estimator (Froot 1989) was used in all regressions to obtain a robust variance estimate that adjusts for within-cluster correlation with regard to study centers

$M C I$ mild cognitive impairment

$* p \leq 0.05 ; * * p \leq 0.01 ; * * * p \leq 0.001$

${ }^{\text {a }}$ Tobit regression

as reflected in the facets intimacy and social participation. The fact that MCI was not associated with social participation can be seen as a potential resource for those affected by MCI, since frequency of engagement in social activities is linked to a lower risk of progression from mild to severe forms of cognitive impairment [11] and social activities are connected to reduced dementia risk [12].

\section{Conclusion}

Results indicate that, especially, autonomy is associated with MCI. In the light of high prevalence of MCI among older people, these results have implications for the management of MCI. For example, participants may benefit from interventions to boost autonomy and/or cope with decreasing independence.

From a methodological point of view, our results show that in order to understand the burden of MCI on the older population, a differentiated approach, using specific facets rather than a total score, is highly recommendable.

From the perspective of research, interactions between facets are of great interest as well as the causal mechanisms and the neuronal, behavioral and psychological processes that link MCI to QOL. Furthermore, future research may differentiate between the effects of amnestic vs. non-amnestic MCI and take into account the severity of impairment. 
Reduced QOL, especially over longer periods of time, may have multiple consequences for individuals on a psychological, physiological, behavioral, and social level. Clearly, more research is needed in this area.

\section{Limitations}

While this study has several advantages, e.g., the comprehensive assessment of MCI and QOL, and a well-described cohort of individuals in late life, our research also has certain limitations. For living situation and the ability to walk, see and hear, answering options were merged for analysis due to the small amount of participants attached to specific options. Further research would benefit from a more differentiated approach to MCI with regard to type, amnestic vs. non-amnestic, and degree of severity. In addition, our analysis is cross sectional which limits our ability to make a causal claim to the findings of the study.

Acknowledgements Open Access funding provided by Projekt DEAL. Members of the AgeCoDe \& AgeQualiDe Study Group. Principal Investigators*: Wolfgang Maier, Martin Scherer, Steffi G. Riedel-Heller. Heinz-Harald Abholz, Christian Brettschneider, Cadja Bachmann, Horst Bickel, Wolfgang Blank, Hendrik van den Bussche, Sandra Eifflaender-Gorfer, Marion Eisele, Annette Ernst, Angela Fuchs, André Hajek, Kathrin Heser, Frank Jessen, Hanna Kaduszkiewicz, Teresa Kaufeler, Mirjam Köhler, Hans-Helmut König, Alexander Koppara, Diana Lubisch, Tobias Luck, Dagmar Lühmann, Melanie Luppa, Tina Mallon, Manfred Mayer, Edelgard Mösch, Michael Pentzek, Jana Prokein, Alfredo Ramirez, Susanne Röhr, Anna Schumacher, Janine Stein, Susanne Steinmann, Franziska Tebarth, Carolin van der Leeden, Michael Wagner, Klaus Weckbecker, Dagmar Weeg, Jochen Werle, Siegfried Weyerer, Birgitt Wiese, Steffen Wolfsgruber, Thomas Zimmermann. *Hendrik van den Bussche (2002-2011)

Author contributions FSH and IC designed the study, performed the statistical analysis, interpreted the results, and drafted the manuscript. SRH and IC contributed to the interpretation of results, and to the revision of the manuscript. SR, AF, MP, HB, EM, SW, JW, BW, SM, $\mathrm{CB}, \mathrm{KH}, \mathrm{LK}, \mathrm{HK}, \mathrm{ME}, \mathrm{WM}, \mathrm{MW}, \mathrm{MS}$, and HHK contributed to data collection and the revision of the manuscript. All authors read and approved the final manuscript.

Funding This publication is part of the German Research Network on Dementia (KND), the German Research Network on Degenerative Dementia (KNDD; German Study on Ageing, Cognition and Dementia in Primary Care Patients; AgeCoDe), and the Health Service Research Initiative (Study on Needs, health service use, costs and health-related quality of life in a large sample of oldest-old primary care patients (85+; AgeQualiDe)) and was funded by the German Federal Ministry of Education and Research (grants KND: 01GI0102, 01GI0420, 01GI0422, 01GI0423, 01GI0429, 01GI0431, 01GI0433, 01GI0434; grants KNDD: 01GI0710, 01GI0711, 01GI0712, 01GI0713, 01GI0714, 01GI0715, 01GI0716; grants Health Service Research Initiative: 01GY1322A, 01GY1322B, 01GY1322C, 01GY1322D, 01GY1322E, $01 \mathrm{GY} 1322 \mathrm{~F}, 01 \mathrm{GY} 1322 \mathrm{G})$. Furthermore, this publication is part of the study "Healthy Aging: Gender specific trajectories into latest life" (AgeDifferent.de) and was funded by the German Federal Ministry of Education and Research (AgeDifferent.de: Funding program "Gesund
- ein Leben lang", grants 01GL1714A; 01GL1714B; 01GL1714C; 01GL1714D). This paper was supported by a grant from the Hans and Ilse Breuer Foundation. We want to thank all participating patients and their general practitioners for their good collaboration.

\section{Compliance with ethical standards}

Conflict of interest The authors declare that they have no conflict of interest.

Ethical approval The AgeCoDe study was conducted in accordance with the Declaration of Helsinki [33] and approved by the local ethic committees of all participating centers. Patients and/or their proxies provided written informed consent.

Informed consent Informed consent was obtained from all individual participants included in the study.

Open Access This article is licensed under a Creative Commons Attribution 4.0 International License, which permits use, sharing, adaptation, distribution and reproduction in any medium or format, as long as you give appropriate credit to the original author(s) and the source, provide a link to the Creative Commons licence, and indicate if changes were made. The images or other third party material in this article are included in the article's Creative Commons licence, unless indicated otherwise in a credit line to the material. If material is not included in the article's Creative Commons licence and your intended use is not permitted by statutory regulation or exceeds the permitted use, you will need to obtain permission directly from the copyright holder. To view a copy of this licence, visit http://creativecommons.org/licenses/by/4.0/.

\section{References}

1. Barberger-Gateau, P., Commenges, D., Gagnon, M., Letenneur, L., Sauvel, C., \& Dartigues, J. F. (1992). Instrumental activities of daily living as a screening tool for cognitive impairment and dementia in elderly community dwellers. Journal of the American Geriatrics Society, 40(11), 1129-1134.

2. Campbell, N. L., Unverzagt, F., LaMantia, M. A., Khan, B. A., \& Boustani, M. A. (2013). Risk factors for the progression of mild cognitive impairment to dementia. Clinics in Geriatric Medicine, 29(4), 873-893. https://doi.org/10.1016/j.cger.2013.07.009.

3. Clement-Carbonell, V., Ferrer-Cascales, R., Ruiz-Robledillo, N., Rubio-Aparicio, M., Portilla-Tamarit, I., \& Cabañero-Martínez, M. J. (2019). Differences in autonomy and health-related quality of life between resilient and non-resilient individuals with mild cognitive impairment International. Journal of Environmental Research and Public Health. https://doi.org/10.3390/ijerph1613 2317.

4. Conrad, I., Matschinger, H., Kilian, R., \& Riedel-Heller, S. G. (2016). WHOQOL-OLD und WHOQOL-BREF : Manual : Handbuch für die deutschsprachigen Versionen der WHO-Instrumente zur Erfassung der Lebensqualität im Alter (1st ed.). Göttingen: Hogrefe.

5. Conrad, I., Matschinger, H., Riedel-Heller, S., von Gottberg, C., \& Kilian, R. (2014). The psychometric properties of the German version of the WHOQOL-OLD in the German population aged 60 and older. Health and Quality of Life Outcomes, 12, 105.

6. Daig, I., \& Lehmann, A. (2007). Verfahren zur Messung der Lebensqualität. Zeitschrift für medizinische Psychologie, 16, 5-23. 
7. Dalton, D. S., Cruickshanks, K. J., Klein, B. E. K., Klein, R., Wiley, T. L., \& Nondahl, D. M. (2003). The impact of hearing loss on quality of life in older adults. The Gerontologist, 43(5), 661-668. https://doi.org/10.1093/geront/43.5.661.

8. Froot, K. A. (1989). Consistent covariance matrix estimation with cross-sectional dependence and heteroskedasticity in financial data. The Journal of Financial and Quantitative Analysis, 24(3), 333. https://doi.org/10.2307/2330815.

9. Fusco, O., Ferrini, A., Santoro, M., Lo Monaco, M. R., Gambassi, G., \& Cesari, M. (2012). Physical function and perceived quality of life in older persons. Aging Clinical and Experimental Research, 24(1), 68-73. https://doi.org/10.1007/BF03325356.

10. Hu, C., Yu, D., Sun, X., Zhang, M., Wang, L., \& Qin, H. (2017). The prevalence and progression of mild cognitive impairment among clinic and community populations: A systematic review and meta-analysis. International Psychogeriatrics, 29(10), 15951608. https://doi.org/10.1017/S1041610217000473.

11. Hughes, T. F., Flatt, J. D., Fu, B., Chang, C.-C. H., \& Ganguli, M. (2013). Engagement in social activities and progression from mild to severe cognitive impairment: The MYHAT study. International Psychogeriatrics, 25(4), 587-595. https://doi.org/10.1017/S1041 610212002086.

12. Hussenoeder, F. S., \& Riedel-Heller, S. G. (2018). Primary prevention of dementia: From modifiable risk factors to a public brain health agenda? Social Psychiatry and Psychiatric Epidemiology, 53(12), 1289-1301. https://doi.org/10.1007/s00127-018-1598-7.

13. Joensen, L. E., Almdal, T. P., \& Willaing, I. (2013). Type 1 diabetes and living without a partner: Psychological and social aspects, self-management behaviour, and glycaemic control. Diabetes Research and Clinical Practice, 101(3), 278-285. https://doi. org/10.1016/j.diabres.2013.07.001.

14. Kameyama, K., Tsutou, A., \& Fujino, H. (2016). The relationship between health-related quality of life and higher-level functional capacity in elderly women with mild cognitive impairment. Journal of Physical Therapy Science, 28(4), 1312-1317. https://doi. org/10.1589/jpts.28.1312.

15. Lapid, M. I., Rummans, T. A., Boeve, B. F., McCormick, J. K., Pankratz, V. S., Cha, R. H., et al. (2011). What is the quality of life in the oldest old? International Psychogeriatrics, 23(6), 1003-1010. https://doi.org/10.1017/S1041610210002462.

16. Lips, P., \& van Schoor, N. M. (2005). Quality of life in patients with osteoporosis. Osteoporosis International, 16(5), 447-455. https://doi.org/10.1007/s00198-004-1762-7.

17. Liu, H.-Y., Tsai, W.-C., Chiu, M.-J., Tang, L.-Y., Lee, H.-J., \& Shyu, Y.-I. L. (2019). Mild cognitive impairment in combination with comorbid diabetes mellitus and hypertension is negatively associated with health-related quality of life among older persons in Taiwan. Quality of Life Research: An International Journal of Quality of Life Aspects of Treatment, Care and Rehabilitation, 28(5), 1281-1291. https://doi.org/10.1007/s11136-019-02101-3.

18. Luck, T., Riedel-Heller, S. G., Kaduszkiewicz, H., Bickel, H., Jessen, F., Pentzek, M., et al. (2007). Mild cognitive impairment in general practice: Age-specific prevalence and correlate results from the German study on ageing, cognition and dementia in primary care patients (AgeCoDe). Dementia and Geriatric Cognitive Disorders, 24(4), 307-316. https://doi.org/10.1159/000108099.

19. Missotten, P., Squelard, G., Ylieff, M., Di Notte, D., Paquay, L., de Lepeleire, J., et al. (2008). Quality of life in older Belgian people: Comparison between people with dementia, mild cognitive impairment, and controls. International Journal of Geriatric Psychiatry, 23(11), 1103-1109. https://doi.org/10.1002/gps.1981.

20. Muangpaisan, W., Assantachai, P., Intalapaporn, S., \& Pisansalakij, D. (2008). Quality of life of the community-based patients with mild cognitive impairment. Geriatrics \& Gerontology International, 8(2), 80-85. https://doi.org/10.111 1/j.1447-0594.2008.00452.x.
21. Parker, P. A., Baile, W. F., Moor, C. D., \& Cohen, L. (2003). Psychosocial and demographic predictors of quality of life in a large sample of cancer patients. Psycho-Oncology, 12(2), 183-193. https://doi.org/10.1002/pon.635.

22. Pusswald, G., Moser, D., Pflüger, M., Gleiss, A., Auff, E., Stögmann, E., et al. (2016). The impact of depressive symptoms on health-related quality of life in patients with subjective cognitive decline, mild cognitive impairment, and Alzheimer's disease. International Psychogeriatrics, 28(12), 2045-2054. https://doi. org/10.1017/S1041610216001289.

23. Ready, R. E., Ott, B. R., \& Grace, J. (2004). Patient versus informant perspectives of quality of life in mild cognitive impairment and Alzheimer's disease. International Journal of Geriatric Psychiatry, 19(3), 256-265. https://doi.org/10.1002/gps.1075.

24. Roberts, R. O., Knopman, D. S., Mielke, M. M., Cha, R. H., Pankratz, V. S., Christianson, T. J. H., et al. (2014). Higher risk of progression to dementia in mild cognitive impairment cases who revert to normal. Neurology, 82(4), 317-325. https://doi. org/10.1212/WNL.0000000000000055.

25. Steinbüchel, N., \& v., Lischetzke, T., Gurny, M., \& Winkler, I., (2005). Erfassung gesundheitsbezogener Lebensqualität älterer Menschen mit dem WHOQOL-BREF-Fragebogen. Zeitschrift für Medizinische Psychologie, 14(1), 13-23.

26. Stelmack, J. (2001). Quality of life of low-vision patients and outcomes of low-vision rehabilitation. Optometry and Vision Science: Official Publication of the American Academy of Optometry, 78(5), 335-342. https://doi.org/10.1097/00006324-20010500000017.

27. Stites, S. D., Karlawish, J., Harkins, K., Rubright, J. D., \& Wolk, D. (2017). Awareness of mild cognitive impairment and mild alzheimer's disease dementia diagnoses associated with lower selfratings of quality of life in older adults. The Journals Of Gerontology. Series B, Psychological Sciences and Social Sciences, 72(6), 974-985. https://doi.org/10.1093/geronb/gbx100.

28. Teng, E., Tassniyom, K., \& Lu, P. (2012). Reduced quality of life ratings in mild cognitive impairment: Analyses of subject and informant responses (P04.208). Neurology, 78(Meeting Abstracts 1), P04.208-P04.208.

29. Teng, E., Tassniyom, K., \& Lu, P. H. (2012). Reduced qualityof-life ratings in mild cognitive impairment: Analyses of subject and informant responses. The American Journal of Geriatric Psychiatry: Official Journal of the American Association for Geriatric Psychiatry, 20(12), 1016-1025. https://doi.org/10.1097/ JGP.0b013e31826ce640.

30. Undén, A.-L., Elofsson, S., Andréasson, A., Hillered, E., Eriksson, I., \& Brismar, K. (2008). Gender differences in self-rated health, quality of life, quality of care, and metabolic control in patients with diabetes. Gender Medicine, 5(2), 162-180. https:// doi.org/10.1016/j.genm.2008.05.003.

31. Weiss, E. M., Papousek, I., Fink, A., Matt, T., Marksteiner, J., \& Deisenhammer, E. A. (2012). Lebensqualität bei älteren Personen mit unterschiedlichem Schweregrad von kognitiver Beeinträchtigung. Neuropsychiatrie: Klinik, Diagnostik, Therapie und Rehabilitation: Organ der Gesellschaft Osterreichischer Nervenarzte und Psychiater, 26(2), 72-77. https://doi.org/10.1007/s4021 1-012-0016-8.

32. Winblad, B., Palmer, K., Kivipelto, M., Jelic, V., Fratiglioni, L., Wahlund, L.-O., et al. (2004). Mild cognitive impairmentbeyond controversies, towards a consensus: Report of the International Working Group on Mild Cognitive Impairment. Journal of Internal Medicine, 256(3), 240-246. https://doi.org/10.111 $1 / \mathrm{j} .1365-2796.2004 .01380 . x$.

33. World Medical Association. (2002). World Medical Association Declaration of Helsinki: Ethical principles for medical research involving human subjects. Journal of Postgraduate Medicine, 48(3), 206-208. 
34. Xu, W., Wang, H.-X., Caracciolo, B., Winblad, B., Bäckman, L., Qiu, C., et al. (2010). Accelerated progression from mild cognitive impairment to dementia in people with diabetes. Alzheimer's \& Dementia, 6(4), S110-S111. https://doi.org/10.1016/j. jalz.2010.05.342.

35. Zaudig, M., \& Hiller, W. (1996). SIDAM-Handbuch : Strukturiertes Interview für die Diagnose einer Demenz vom Alzheimer Typ, Multiinfarkt- (oder vaskulären) Demenz und Demenzen anderer Ätiologie nach DSM-III-R, DSM-IV und ICD-10. Bern: Huber.

Publisher's Note Springer Nature remains neutral with regard to jurisdictional claims in published maps and institutional affiliations. 